\title{
The prevalence of hepatitis A antibodies in HIV exposed and/or infected children and adolescents
}

\author{
Aída F. T. B. Gouvêa, ${ }^{1}$ Maria Isabel de Moraes-Pinto, ${ }^{2}$ Daisy M. Machado, ${ }^{3}$ \\ Fabiana B. do Carmo, ${ }^{1}$ Suênia C. V. Beltrão, ${ }^{1}$ Kelly S. Cunegundes, ${ }^{1}$ Silvana D. Pessoa, ${ }^{1}$ \\ Lily Yin Weckx, ${ }^{4}$ Regina Célia M. Succi ${ }^{5}$
}

\begin{abstract}
Objective: To evaluate the prevalence of hepatitis A virus antibodies in HIV-exposed and/or HIV-infected children and adolescents.

Methods: Between September 1996 and August 2002, 352 patients (200 exposed, but not HIV-infected and 152 HIV exposed and infected) were included in this study. These children and adolescents (age ranged between 1 and 14 years) were all followed up at the Pediatric AIDS Clinic of the Federal University of São Paulo (UNIFESP) and had anti-HAV antibodies determined by a commercially available ELISA method (tests for total anti-HAV antibodies and specific IgM antibodies) (Dia Sorin and Radim). Statistical analyses were done with chi-squared and $t$ test.

Results: The prevalence of hepatitis A virus antibodies in HIV-infected and HIV-exposed, but uninfected patients was $34 \%$ and $19.7 \%$, respectively. We noticed that in the age range between 2 years and 10 years, the group of HIVinfected children presented a higher prevalence of hepatitis A virus antibodies (35.5\%) than the group of uninfected children $(16.7 \%)(p=0.005)$. In the HIV infected group, children from $B$ and $C$ categories had a prevalence of hepatitis A virus antibodies $(40.5 \%)$ higher than $N$ and $A$ categories $(24.1 \%)(p=0.042)$. Mean age did not differ when children from $B$ and $C$ categories were compared with $N$ and $A$ categories ( 5.18 and 5.66 years, respectively) $(p=0.617)$.

Conclusions: The prevalence of hepatitis A virus antibodies in HIV exposed and/or infected children and adolescents between 1 and 14 years old was $26 \%$. Considering the possibility of HIV infection aggravation when associated with hepatitis A virus infection, we suggest that hepatitis A virus inactivated vaccine should be administered to these patients.
\end{abstract}

J Pediatr (Rio J). 2005;81(3):205-8: Hepatitis A, epidemiology, acquired immunodeficiency syndrome, HIV.

\section{Introduction}

Hepatitis $A$ is an acute viral disease classically characterized as benign. Transmission occurs via the fecal-oral route, which can be person to person or via contaminated water or food.

1. Pediatrician, Pediatric Infectious Disease Clinic, Universidade Federal de São Paulo (UNIFESP), São Paulo, SP, Brazil.

2. PhD. Professor and chief of the Pediatric Infectious Disease Clinic, UNIFESP, São Paulo, SP, Brazil.

3. PhD. Professor and pediatrician, Pediatric Infectious Disease Clinic, UNIFESP, São Paulo, SP, Brazil.

4. PhD. Professor, Department of Pediatrics, UNIFESP. Chief of the Reference Center of Special Immunobiologic Products, UNIFESP, São Paulo, SP, Brazil.

5. PhD. Professor, Department of Pediatrics, UNIFESP. Chief of the Pediatric Infectology Service, UNIFESP, São Paulo, SP, Brazil.

Financial support: FADA (Fund for Professor and Student Support) from UNIFESP.

Manuscript received Sep 30 2004, accepted for publication Jan 122005.

Suggested citation: Gouvêa AF, de Moraes-Pinto MI, Machado DM, do Carmo FB, Beltrão SC, Cunegundes KS, et al. The prevalence of hepatitis A antibodies in HIV exposed and/or infected children and adolescents. J Pediatr (Rio J). 2005;81:205-8.
In children, the disease is generally asymptomatic or has mild clinical manifestations, in contrast with adults when the course of the disease is predominantly symptomatic. The probability of developing jaundice increases with age: it is $7 \%$ between 0 and 4 years, $37 \%$ from 5 to $9,70 \%$ from 10 to 17 and $85 \%$ from 18 years of age onwards. ${ }^{1}$ Rarely fatal, hepatitis $A$ does not progress with carriers or chronic forms of the disease; in adults, there may be more severe developments, with a greater proportion of prolonged and polyphasic forms of the disease and a greater frequency of the cholestatic and fulminating forms of the disease, the last one is extremely serious.

Fulminating hepatitis $A$ is a rare event, occurring in something around $0.008 \%$ of the Hepatitis A cases. ${ }^{2}$ The following factors that can be of importance in the development of liver failure in pediatric sufferers of hepatitis A cases: dimension of inoculate, genetic background of the host and the presence of concurrent infections. ${ }^{2}$ Despite the rarity of the severe form of 
hepatitis A, $20 \%$ of pediatric liver transplantations in Argentina are the result of hepatitis $A .{ }^{3}$

Some studies have suggested that acute hepatitis $A$ acts as a possible "trigger" for the development of autoimmune hepatitis in susceptible individuals: people who exhibit a defect in T lymphocyte suppressors may develop chronic autoimmune hepatitis when exposed to the hepatitis A virus (HAV). 4,5

The virus for acquired immunodeficiency (HIV) can impact on the clinical course of hepatitis $A, 6,7$ while, on the other hand, HAV-infection may be linked with a prolonged increase in the HIV-viral load. 8,9

Concerned by the existence of this co-infection in our pediatric population, and accepting that the base liver disease (which, in such children, may equally be the consequence of HIV itself, or of opportunistic infections and anti-retroviral therapy) increases the risk of fulminating hepatitis, we decided to investigate the frequency of HAV infection among children exposed to and/or infected by HIV.

\section{Patients and methods}

This research project was approved by the Committee for Ethics in Research at the Hospital São Paulo/Universidade Federal de São Paulo (UNIFESP). The study investigated the medical records of 352 children born to HIV seropositive mothers and followed-up at the Division of Pediatric Infectious Disease Clinic (CEADIPE) at the UNIFESP/EPM in São Paulo during the period from September 1996 to August 2002. Data from the medical record (identification, age, HAV serology, clinical and immunological classification of HIV infection) were stored in Microsoft Excel 97.

HIV-infected children were classified clinically and immunologically according to the CDC's 1994 standards: 10 clinical categories: $N$ (absence of AIDS symptoms), A (mild symptoms), B (moderate symptoms), C (severe symptoms). Immunological categories: 1 (no immune system suppression according to CD4 T lymphocyte counts), 2 (moderate immune system suppression), 3 (severe immune system suppression).

A qualitative test for total anti-HAV antibodies was performed as part of routine workup using a laboratory test that is commercially available in our country. The test employs the competitive enzyme immunoassay (ELISA) technique and is manufactured by DiaSorin and Radim, both Italian. Results were defined as positive, negative or borderline according to positive and negative controls. A cutoff value was calculated, below which the sample was classified as positive and above which negative. Tests whose absorbance was within the gray area, which is more or less $20 \%$ of the cutoff value, were defined as borderline. Antibody levels greater than $20 \mathrm{mIU} / \mathrm{ml}$ were considered protective. Qualitative IgM antibody detection was performed by means of the immunoenzymatic capture assay (IEMA) or "sandwich ELISA". These tests were all performed at the Central Laboratory at the Hospital São Paulo.
Statistical analysis used the chi-square test to compare the age groups of the two study groups and the test in order to compare the mean age of patients in each of the clinical categories within the HIV-infected group of children. The significance level employed was 0.05.

\section{Results}

The initial study population consisted of 352 patients, of whom 177 (50.3\%) were female and 175 (49.7\%) were male.

Seventeen children were excluded as they exhibited borderline or indefinite serology for HAV: five $(3.28 \%)$ patients in the HIV group (HIV) and $12(6 \%)$ patients in the group of uninfected children (S/R). Thus, the number of children evaluated in the HIV group was 147 and in the S/R group 188 children, making a total of 335 children. The mean age of the HIV group was 4.6 years and it was 2.5 years in the $S / R$ group $(p<0.0001)$. The majority of the children in the HIV group were female and in the $S / R$ group the majority were male $(p=0.011)$ (Table 1$)$.

It is important to point out that none of the children analyzed in this study had been given vaccine against HAV. Furthermore, none of the children had been given immunoglobulin or blood products during the previous 6 months.

The prevalence of total HAV antibodies was greater in the HIV group ( $p=0.003$ ) when compared with the SR group (Table 2). HIV-infected children with presented greater seroprevalence in comparison with the group of HIV uninfected children in all of the age groups studied (Table 3 ) and this difference was statistically significant for the 2 to 10 year age group ( $p=0.005)$.

Fifty out of 147 (34\%) HIV-infected patients (34\%) presented positive serology for HAV. We stratified the group according to clinical and immunological criteria (CDC, 1994) $)^{10}$ applied at the point of collection for HAV serology. Children in clinical categories B and C (moderately and severely symptomatic) were taken together and

Table 1 - Characteristics of patients in the HIV and S/R groups according to age and sex

\begin{tabular}{|c|c|c|c|c|c|}
\hline \multicolumn{6}{|c|}{ Group } \\
\hline & \multicolumn{2}{|r|}{ HIV } & \multicolumn{2}{|c|}{ S/R } & $\mathbf{p}$ \\
\hline \multicolumn{6}{|l|}{ Age (years) } \\
\hline Mean & & 4.6 & & & $<0.0001 *$ \\
\hline Standard deviation & & 3.1 & & & \\
\hline Median & & 3.4 & & & \\
\hline Sex & $\mathbf{n}$ & $(\%)$ & $\mathbf{n}$ & $(\%)$ & \\
\hline \multicolumn{6}{|l|}{ Female } \\
\hline \multirow[t]{2}{*}{ Male } & 84 & (57.1) & 81 & $(43.1)$ & $0.011^{+}$ \\
\hline & 63 & $(42.9)$ & 107 & (56.9) & \\
\hline
\end{tabular}

\footnotetext{
* $\mathrm{p}$ - value obtained with the $t$-test for unequal variance.

$\dagger p$ - value obtained with the chi-square test.

$\mathrm{S} / \mathrm{R}=$ serum-reverted.
} 
compared with those in the clinical categories $\mathrm{A}$ and $\mathrm{N}$ (oligosymptomatic and no symptoms). For immunological classification children classified as 1 (no immunosuppression) were grouped with children classified as 2 and 3 (moderate immunosuppression and severe immunosuppression). We found that there was no association between immunological category and the presence of anti-HAV antibodies, although HIV-class B and $\mathrm{C}$ children presented a greater proportion of HAV seropositive children $(40.5 \%)$ when compared with HIVclass $\mathrm{N}$ and $\mathrm{A}$ ones $(24.1 \%)(p=0.042)$ (Table 4$)$.

Table 2 - Prevalence of total hepatitis A virus antibodies (second group)

\begin{tabular}{|c|c|c|c|}
\hline \multirow[b]{2}{*}{ Presence of IgG } & \multicolumn{2}{|c|}{ Group } & \multirow[b]{2}{*}{ Total } \\
\hline & $\begin{array}{c}\text { HIV } \\
(n=147)\end{array}$ & $\begin{array}{c}S / R \\
(n=188)\end{array}$ & \\
\hline Positive & $50(34 \%)$ & $37(19.7 \%)$ & $87(26 \%)$ \\
\hline Negative & $97(66 \%)$ & $151(80.3 \%)$ & $248(74 \%)$ \\
\hline
\end{tabular}

$\mathrm{S} / \mathrm{R}=$ serum-reverted.

Table 3 - Sample stratification by age range of children with positive serology for hepatitis A virus (second group)

\begin{tabular}{lccc}
\hline $\begin{array}{l}\text { Age range } \\
\text { (years) }\end{array}$ & $\begin{array}{c}\text { HIV } \\
(\mathbf{n}=\mathbf{1 4 7})\end{array}$ & $\begin{array}{c}\mathbf{S} / \mathbf{R} \\
(\mathbf{n}=\mathbf{1 8 8})\end{array}$ & $\mathbf{p} *$ \\
\hline $1-2$ & $6 / 24(25 \%)$ & $24 / 110(21.8 \%)$ & 0.735 \\
$2-10$ & $39 / 110(35.5 \%)$ & $13 / 78(16.7 \%)$ & 0.005 \\
$\geq 10$ & $5 / 13(38.5 \%)$ & - & \\
\hline
\end{tabular}

* $p$-value obtained with the chi-square test.

$\mathrm{S} / \mathrm{R}=$ serum-reverted.

Table 4 - Distribution of HIV-infected patients according to clinical and immunological categories applied at the moment of collection for HAV serology

\section{Presence of anti-HAV} antibodies

\begin{tabular}{lccc}
$\begin{array}{l}\text { Category of } \\
\text { HIV infection }\end{array}$ & Positive & Negative & p * \\
\hline $\begin{array}{l}\text { Clinical } \\
N+A\end{array}$ & $14(24.1 \%)$ & $44(75.9 \%)$ & \\
B + C & $36(40.5 \%)$ & $53(59.5 \%)$ & 0.042 \\
Immunological & & & \\
1 & $9(28.1 \%)$ & $23(71.9 \%)$ & \\
$2+3$ & $41(36.3 \%)$ & $72(63.7 \%)$ & 0.392 \\
\hline
\end{tabular}

Obs.: Immunological category information of two patients not found. ${ }^{*} p=$ chi-square.
It is worth noting that the mean age of HAV seropositive children was similar among those in the HIV group classed clinically as $\mathrm{N}$ and $\mathrm{A}$ (mean of 5.7 years and standard deviation of 2.6 years) and those classed clinically as $B$ and $C$ (mean of 5.2 years, and a standard deviation of 3.2 years) $(t$ test $=0.617)$.

\section{Discussion}

Within the general population, the prevalence of HAV antibodies varies according to age, local epidemiological conditions, socioeconomic status and basic sanitation in different regions worldwide. ${ }^{11-15}$ Research undertaken in Brazil show that the prevalence of HAV antibodies is directly proportional to age and inversely proportional to socioeconomic level. ${ }^{16-18}$

In our research, the prevalence of antibodies against HAV among the 335 HIV exposed and/or infected children tested was $26 \%$ (Table 2 ). These data are compatible with figures published by Ferreira et al. ${ }^{19}$ in 2002, studying children and adolescents with chronic liver disease in the State of Rio Grande do Sul.

The greater prevalence of HAV antibodies among infected children (34\%) in comparison with the uninfected ones $(19.7 \%)$, was probably the consequence of differences in age between the two groups, since the mean ages of the two populations was distinct ( 4.6 years in the HIV group HIV and 2.5 years for the uninfected group) (Table 1 ). With the intention of obtaining comparable groups, we excluded children between 1 and 2 years old from the HIV group (due to the significant difference in the number of patients between the two groups in this age group) and also those aged more than ten years (since there were no children in this age range in the uninfected group). Comparing the two groups of children aged 2 to 10 years, we observed that HAV seroprevalence was $35.5 \%$ for the HIV group, and $16.7 \%$ for the S/R group, reinforcing the greater HAV seroprevalence in the HIV group. Considering that the prevalence of HAV antibodies tends to increase with age, we compared the two study groups by means of stratification by age group (Table 3). While the prevalence of antibodies against HAV tends to be greater among the group of patients infected by HIV when compared with the group of uninfected children, the difference was statistically significant only in the age group from 2 to 10 years of age.

Focaccia et al., ${ }^{18}$ evaluating the general population of São Paulo in 1998, found that the prevalence of HAV antibodies was $21.9 \%$ between 2 and 9 years of age. The difference in relation to the pediatric HIV-infected population in our study may be the consequence of the socio-economic level of the two populations evaluated. Focaccia et al. ${ }^{18}$ studied the general population with individuals belonging to all socioeconomic classes, in contrast with the majority of children who attend the Pediatric Infectious Disease Clinic are from less favored economic classes according to the ANEP. 20

It is interesting to observe that children exhibiting moderate and severe HIV symptomology (categories B and 
C) also exhibited greater prevalence rates of HAV antibodies when compared with children without symptoms or with mild symptoms (categories $\mathrm{N}$ and $\mathrm{A}$ ) (chi-square, $\mathrm{p}=0.042$ ) (Table 4). Considering that this greater prevalence might be related to the greater age of the moderately and severely ill patients, we compared the mean ages of the two groups and found that they were similar (5.7 years for the $N$ and A group and 5.2 years for the $B$ and $C$ group, $p=0.617$ ). We did not find any explanation for this difference in seroprevalence.

In relation to $\mathrm{HIV}$-infected children aged 10 to 14 years, seroprevalence was compatible with data from Focaccia et al.. ${ }^{18}$ Considering that the seroprevalence of HAV antibodies among HIV-infected children increased with age up to 10 years and then dropping among those from 10 to 14 years old, we could infer that these patients might lose their HAV antibodies during adolescence. Our results for patients over ten should be treated with caution, since the sample for this age range was small.

Taking into consideration the fact that moderately and severely HIV-symptomatic patients presented greater HAV seroprevalence and that this group of children is more subject to opportunist infections and liver toxicity due to the anti-retroviral drugs they are given, we emphasize the need to prevent liver damage by means of vaccinal prophylaxis for all HIV-infected patients.

\section{References}

1. Armstrong GL. Hepatitis A infections in United States: modelbased estimates and implications for childhood immunization. Pediatrics. 2002;109:839-45.

2. Shah $U$, Habib $Z$, Kleinman RE. Liver failure attributable to hepatitis A virus infection in a developing country. Pediatrics. 2000;105:436-8.

3. Ciocca M. Clinical course and consequences of hepatitis $A$ infection. Vaccine. 2000;18:S71-4.

4. Jonas MM. Viral hepatitis. In: Allan Walker V, editor. Pediatric gastrointestinal disease. 2nd ed. Missouri: Mosby-Year Book. Inc.; 1996. p. 1028-1051.

5. Vento S, Garofano T, DiPerri G. Identification of hepatitis A virus as a trigger for autoimmune chronic hepatitis type I in susceptible individuals. Lancet. 1991;337:1183-7.

6. Ida S, Tachikawa N, Nakajima A, Daikoku M, Yano M, Kikuchi Y, et al. Influence of human immunodeficiency virus type 1 infection on acute hepatitis A virus infection. Clin Infect Dis. 2002;34:379-85.
7. Costa-Mattioli M, Allavena C, Poirier AS, Billaudel S, Raffi F, Ferré V. Prolonged hepatitis A infection in an HIV-1 seropositive patient. J Med Virol. 2002;68:7-11.

8. Wallace MR, Hill HE, Tasker SA, Miller LK. Hepatitis A in human immunodeficiency Virus-Infected Patients. Clin Infect Dis. 1998;27:651-3.

9. Ridolfo AL, Rusconi S, Antinori S, Balotta C, Galli M. Persisting HIV-1 replication triggered by acute hepatitis A virus infection. Antiviral Therapy. 2000;5:15-18.

10. Centers for Disease Control and Prevention :1994 Revised classification system for human immunodeficiency virus infection in children less than 13 years of age. MMWR Morb Mortal Wkly Rep. 1994;43:1-17.

11. Cianciara J. Hepatitis A shifting epidemiology in Poland and Eastern Europe. Vaccine. 2000;18:S68-70.

12. Bargaza NG. Hepatitis A shifting epidemiology in south-east Asia and China. Vaccine. 2000;18:561-4.

13. Tufenkeji $\mathrm{H}$. Hepatitis A shifting epidemiology in the Middle East and Africa. Vaccine. 2000;18:S65-7.

14. Tanaka J. Hepatitis A shifting epidemiology in Latin America. Vaccine. 2000;18:S57-60.

15. Tapia-Conyer R, Santos JI, Cavalcanti AM, Urdaneta E, Rivera L, Manterola A, et al. Hepatitis A in Latin America: a changing epidemiologic pattern. Am J Trop Med Hyg. 1999;61:825-9.

16. Pannuti CS, Mendonça JS, Carvalho MJ. Hepatitis A antibodies in two socioeconomically distinct populations of São Paulo, Brazil. Rev Inst Med Trop São Paulo. 1985;27:162-4.

17. Pinho JR, Sumita LM, Moreira RC, Souza VA, Saraceni CP, Oba IT, et al. Duality of patterns in hepatitis A epidemiology: A study involving two socioeconomically distinct populations in Campinas, São Paulo state, Brazil. Rev Inst Med Trop São Paulo. 1998;40:105-6.

18. Focaccia R, Conceição OJ, Sette H Jr, Sabino E, Bassit L, Nitrini $D R$, et al. Estimated Prevalence of Viral Hepatitis in the General Population of the Municipality of São Paulo, Measured by Serologic Survey of a Stratified, Randomized and ResidenceBased Population. Braz J Infect Dis. 1998;2:269-84.

19. Ferreira CT, Taniguchi AN, Vieira SM, Lima JP, Silveira TR. Prevalência do anticorpo da hepatite A em crianças e adolescentes com hepatopatia crônica. J Pediatr. 2002;78:503-8.

20. ANEP - Associação Nacional de Empresas de Pesquisa. Critério de classificação econômica. Brasil, 2002. Disponível em: http://www.anep.org.br.

Correspondência:

Regina Célia M. Succi

Rua Pedro de Toledo, 924, Vila Clementina

CEP 04039-002 - São Paulo, SP, Brazil

E-mail: succi@picture.com.br 